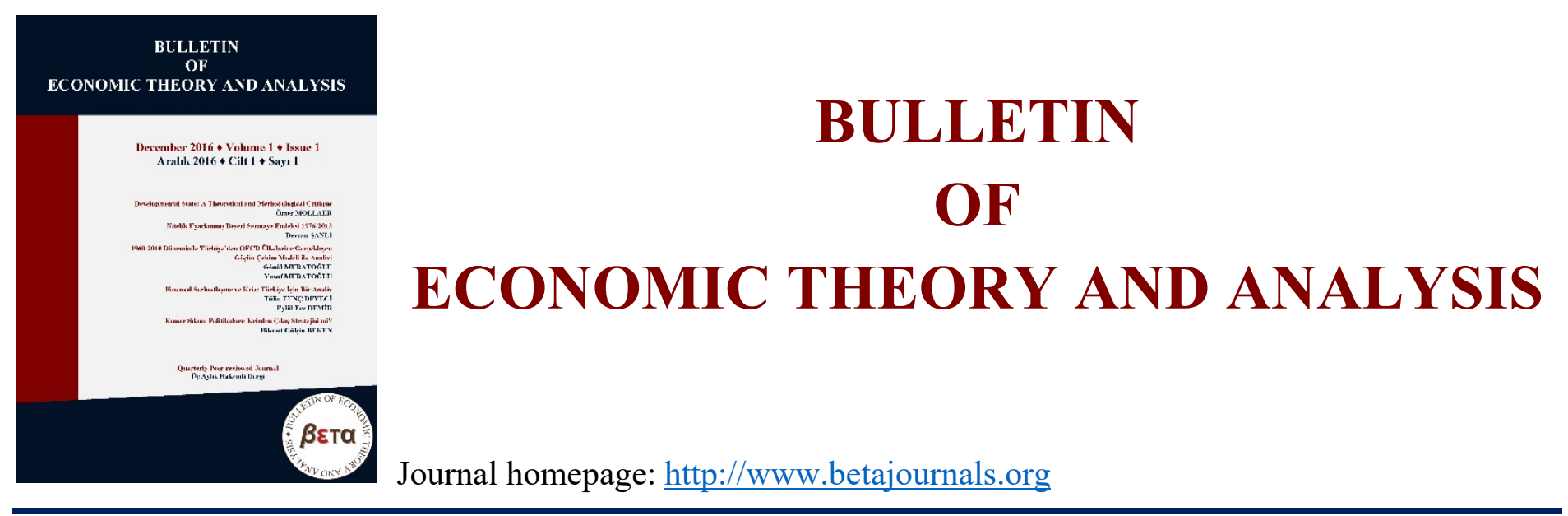

\title{
The Impact of Imported Energy and Goods Prices on Growth and Trade Balance of a Small Open Economy
}

\section{Wei-Bin ZHANG}

To cite this article: ZHANG, W. B. (2017). The Impact of Imported Energy and Goods Prices on Growth and Trade Balance of a Small Open Economy. Bulletin of Economic Theory and Analysis, 2(2), 99-116.

Received: 18 Jan 2017

Accepted: 11 May 2017

Published online: 30 Jun 2017

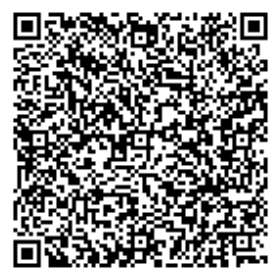




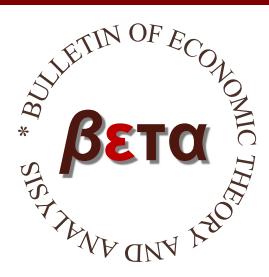

\title{
Bulletin of Economic Theory and Analysis
}

Volume II, Issue 2, pp. 99-116, 2017

http://www.betajournals.org

\section{The Impact of Imported Energy and Goods Prices on Growth and Trade Balance of a Small Open Economy}

\author{
Wei-Bin ZHANG $^{\mathrm{a}}$ \\ a Prof. Ph.D., Ritsumeikan Asia Pacific University, JAPAN
}

\begin{abstract}
This study builds a growth model of a small open economy with imported energy and goods in a perfectly competitive economy. The economy is composed of one industrial sector and one service sector. The economy is endowed with constant labor and land. The growth mechanism is basically neoclassical in the sense that the main determinant of growth is endogenous wealth. This study is mainly concerned with the effects of changes in capital cost, energy price and price of imported goods on trade balance, price of services, land rent, and path of economic growth. The comparative dynamic analysis provides some insights into the impact of exogenous shocks on the national economy.
\end{abstract}

Keywords Price of Energy, Price of Imported Goods, Propensity to Consume Foreign Goods, Propensity to Save, Small Open Economy

JEL Classification F43, L83.

CONTACT Wei-Bin ZHANG, $\bowtie$ wbz1@apu.ac.jp $\cong$ Ritsumeikan Asia Pacific University, JAPAN

ACKNOWLEDGEMENTS I am thankful for the important comments of the three anonymous referees. The research supported by Project No. 25380246, the Grants-in-Aid for Scientific Research (C), Japan Society for the Promotion of Science. 


\section{Introduction}

The purpose of this study is to analyze how a small open economy without energy react to changes in global economies. Possible effects of disturbances such as global economic crisis and prices of input factors have caused attention of economists for long time (e.g.,, Sachs, 1982; Svensson and Razin, 1983; Matsuyama, 1987). As far as small economies are concerned, the main concerns in global economic changes are prices of energy and imported goods. This paper deals with the response of economic growth and trade balance due to changes in prices of imported energy, prices of imported goods, the preference for imported goods, and the propensity to save for a small open economy. We are concerned with effects of imported energy in the traditional neoclassical growth theory. Our attention is focused on energy as it is an important part of some small economies, such as Hong Kong and Singapore. Moreover, it is well known that the energy crises in the 1970s and recent years had strong effects on the economic structure and growth of some small economies. As different sectors and households need energy, a change in the price of energy in global market may affect the energy-poor national economy in different ways (Kim and Loungani, 1992; Backus and Crucini, 2000). In order to comprehensively study possible effects of the price of energy on national economic development and economic structure, it is necessary to deal with the issues within a dynamic general equilibrium framework. This study studies the price of energy and economic growth on basis of Uzawa's two-sector growth model in context of a small-open economy.

We are also concerned with issues about how changes in the preference for foreign goods affect the economic structure and economic growth. Preferences for domestic goods or foreign goods are significant for understanding the impact of trade on domestic growth. The effects of foreign goods on national economic structure and growth are always in political debates. This study examines effects of the preference for foreign goods on trade balance and short-run as well as longrun economic growth. In order to properly study with dynamic interactions between growth, energy, preference for foreign goods and trade balance, we obviously need a genuine dynamic general equilibrium framework. Nevertheless, only a few dynamic economic models of small open economies are constructed to examine these dynamic issues in a general equilibrium framework on microeconomic foundation. This study constructs a nonlinear dynamic model on the basis of the neoclassical growth theory and the growth models with energy for small-open economies. The 
model is an integration of the basic features of the three well-known economic growth models. They are the Solow growth model, the two-sector growth model of Uzawa (1961), and the growth models for small open economies with imported energies. It is specially influenced by a model by Schubert and Turnovsky (2011). Schubert and Turnovsky study a small energyimporting economy where production depends upon labor, capital, and imported energy (oil). We deviate from the traditional models for open small economies in that land and housing are taken in account in the same way as in a small-open growth model by Zhang (2013). This study introduces imported energy and imported good into Zhang's model, emphasizing influences of global economic conditions on small open economies. We organize the study as follows. Section 2 develops the model for a small open economy with imported energy. Section 3 expresses the motion of the economic system in a set of differential equations and simulates the motion of the system. Section 4 conducts comparative dynamic analysis with regard to some parameters. Section 5 concludes the study. The appendix checks the results in Section 3.

\section{The Model with Imported Goods and Energy}

This study is concerned with an economy which is small and open. The economy produces two goods: an internationally traded good (called industrial good) and a non-traded good (called services). This classification for small-open growth economy is similar to Brock (1988). Brock classifies goods and services as traded and non-traded. In order to examine effects of terms of trade and foreign trade, following the model of Eicher et al. (2008), we include another good, called imported good. The national economy does not produce this good. Domestic consumers consume imported good. This good is not produced by the economy, but consumed by the domestic consumers. The open economy can borrow resources from the rest of the world or exports goods and lend resources abroad. The price of the industrial good is unity. The depreciation rate $\delta_{k}$ is constant. The small open economy implies that the world interest rate $r^{*}$, price of imported goods $p_{Z}$, and price of imported energy $p_{x}$. are given in global markets. The wealth and land are owned by the households. The representative household receives income from wages, land rent, and interest payments of wealth. Land is only for residential and service use. We assume that technologies of the production sectors are neoclassical. All markets are perfectly competitive. Capital and labor are completely mobile between the two sectors. Capital is perfectly mobile in international market. There is no international emigration or/and 
immigration. We assume that labor is homogeneous and is fixed.

\subsection{The Industrial Sector}

Let subscript index, $i$ and $s$, denote respectively the industrial and service sectors. We use $K_{j}(t)$ and $N_{j}(t)$ to denote the capital stocks and labor force employed by sector $j, j=i, s$, at time $t$. Let $X_{j}(t)$ stand for the amount of energy used by sector $j, j=i, s$. We use $F_{j}(t)$ to represent the output level of sector $j$. The production function of the industrial sector is taken on the following form

$$
F_{i}(t)=A_{i} K_{i}^{\alpha_{i}}(t) N_{i}^{\beta_{i}}(t) X_{i}^{b_{i}}(t), \alpha_{i}, \beta_{i}, b_{i}>0, \alpha_{i}+\beta_{i}+b_{i}=1,
$$

where $A_{i}, \alpha_{i}, \beta_{i}$, and $b_{i}$, are parameters. Markets are competitive. Labor and capital are paid according to their marginal products. Firms earn zero profits. The wage rate, $w(t)$, is determined in domestic labor market. The marginal conditions for the industrial sector imply

$$
r_{\delta}=\alpha_{i} A_{i} k_{i}^{\alpha_{i}-1}(t) x_{i}^{b_{i}}(t), w(t)=\beta_{i} A_{i} k_{i}^{\alpha_{i}}(t) x_{i}^{b_{i}}(t), \quad p_{x}=b_{i} A_{i} k_{i}^{\alpha_{i}}(t) x_{i}^{b_{i}-1}(t),
$$

where

$$
k_{i}(t) \equiv \frac{K_{i}(t)}{N_{i}(t)}, x_{i}(t) \equiv \frac{X_{i}(t)}{N_{i}(t)}, r_{\delta} \equiv r^{*}+\delta_{k}
$$

From (2) we solve

$$
k_{i}=\left(\frac{b^{b_{i}-1} b_{i} A_{i}}{p_{x}}\right)^{1 / \beta_{i}}, x_{i}=b k_{i}, w=\beta_{i} A_{i} k_{i}^{\beta_{i}} x_{i}^{b_{i}},
$$

where $b \equiv b_{i} r_{\delta} / \alpha_{i} p_{x}$. The capital and energy intensities and wage rate are expressed as functions of the rate of interest and the price of energy.

\subsection{The Service Sector}

We take account of four inputs, capital $K_{s}(t)$, labor force $N_{s}(t)$, energy $X_{s}(t)$, and land $L_{s}(t)$ in service supply. We specify the production function of the service sector as follows

$$
F_{s}(t)=A_{s} K_{s}^{\alpha_{s}}(t) N_{s}^{\beta_{s}}(t) X_{s}^{b_{s}}(t) L_{s}^{\gamma_{s}}(t), \alpha_{s}, \beta_{s}, b_{s}, \gamma_{s}>0, \alpha_{s}+\beta_{s}+b_{s}+\gamma_{s}=1 \text {, }
$$


where $A_{s}, \alpha_{s}, \beta_{s}, b_{s}$, and $\gamma_{s}$ are parameters. Let $p(t)$ and $R(t)$ stand respectively for the price of the service and the land rent. The marginal conditions for the service sector imply

$$
\begin{aligned}
& r_{\delta}=\alpha_{s} A_{s} p(t) k_{s}^{\alpha_{s}-1}(t) x_{s}^{b_{s}}(t) l_{s}^{\gamma_{s}}(t), \quad w=\beta_{s} A_{s} p(t) k_{s}^{\alpha_{s}}(t) x_{s}^{b_{s}}(t) l_{s}^{\gamma_{s}}(t), \\
& p_{x}=b_{s} A_{s} p(t) k_{s}^{\alpha_{s}}(t) x_{s}^{b_{s}-1}(t) l_{s}^{\gamma_{s}}(t), \quad R(t)=\gamma_{s} A_{s} p(t) k_{s}^{\alpha_{s}}(t) x_{s}^{b_{s}}(t) l_{s}^{\gamma_{s}-1}(t),
\end{aligned}
$$

where

$$
k_{s}(t) \equiv \frac{K_{s}(t)}{N_{s}(t)}, \quad x_{s}(t) \equiv \frac{X_{s}(t)}{N_{s}(t)}, l_{s}(t) \equiv \frac{L_{s}(t)}{N_{s}(t)}
$$

From (5) we get

$$
k_{s}=\frac{\alpha_{s} w}{\beta_{s} r_{\delta}}, \quad x_{s}=\frac{b_{s} r_{\delta}}{\alpha_{s} p_{x}} .
$$

The variables $k_{s}$ and $x_{s}$ are functions of the rate of interest and the price of energy.

\subsection{Full Employment of Capital and Labor}

We use $K(t)$ to stand for the total capital stocks employed by the country. The total capital stock is employed by the two sectors. Let $N$ represent for the fixed population. The assumption of full employment of labor and capital implies

$$
K_{i}(t)+K_{s}(t)=K(t), \quad N_{i}(t)+N_{s}(t)=N .
$$

The above equations are rewritten as

$$
k_{i} N_{i}(t)+k_{s} N_{s}(t)=K(t), \quad N_{i}(t)+N_{s}(t)=N .
$$

Equations (3) and (6) determine the capital intensities of the two sectors, $k_{i}$ and $k_{s}$, functions of $r^{*}$ and $p_{x}$. From (7), we get

$$
N_{i}(t)=\left(K(t)-k_{s} N\right) k_{0}, N_{s}(t)=\left(k_{i} N-K(t)\right) k_{0},
$$

where $k_{0} \equiv\left(k_{i}-k_{s}\right)^{-1}$. We require $k_{0} \neq 0$. The total capital employed by the country determines the labor distribution.

\subsection{Behavior of Domestic Households}

This study applies an alternative way proposed by Zhang (2005) to describe behavior of households. We use $L$ and $R(t)$ to stand for the land and land rent, respectively. The representative household gets income from land ownership, wealth and wage. It is assumed that the households 
equally own the national land. The total land revenue is $L R(t)$. The income from land per household is $\bar{r}(t)=L R(t) / N$. The household chooses lot size, consumption levels of industrial goods, imported goods, imported energy, and services, and saving. We define the current income as

$$
y(t)=r^{*} \bar{k}(t)+w+\bar{r}(t),
$$

where $r^{*} k$ is the interest payment, $w$ the wage payment, and $\bar{r}$ the land rent income. The disposable income at any point in time is

$$
\hat{y}(t)=y(t)+\bar{k}(t) .
$$

The disposable income is distributed between saving and consumption. At time $t$ the representative household owns the total disposable income $\hat{y}$ to distribute between consuming and saving. The representative household uses the total available budget to choose the lot size $l(t)$, consumption of services $c_{s}(t)$, industrial goods $c_{i}(t)$, imported goods $c_{Z}(t)$, energy consumption $c_{x}(t)$, and saving $s(t)$. The budget constraint is

$$
R(t) l(t)+p(t) c_{s}(t)+c_{i}(t)+p_{Z} c_{Z}(t)+p_{x} c_{x}(t)+s(t)=\hat{y}(t) .
$$

From (11) we see that the household's disposable income is used for the consumption and saving. The utility $U(t)$ is assumed to be related to $l(t), c_{s}(t), c_{i}(t), c_{x}(t)$ and $s(t)$ as follows

$$
U(t)=\theta l^{\eta_{0}}(t) c_{s}^{\gamma_{0}}(t) c_{i}^{\xi_{0}}(t) c_{Z}^{\varsigma_{0}}(t) c_{x}^{\chi_{0}}(t) s^{\lambda_{0}}(t), \eta_{0}, \gamma_{0}, \xi_{0}, \varsigma_{0}, \chi_{0}, \lambda_{0}>0,
$$

in which $\eta_{0}, \gamma_{0}, \xi_{0}, \varsigma_{0}, \chi_{0}$, and $\lambda_{0}$ are the consumer's elasticity of utility with regard to the lot size, services, industrial goods, imported good, energy consumption, and saving. We call $\eta_{0}$, $\gamma_{0}, \xi_{0}, \varsigma_{0}, \chi_{0}$, and $\lambda_{0}$ propensities to consume the lot size, to consume services, to consume industrial goods, to consume imported goods, to consume energy, and to hold wealth, respectively. Maximizing $U(t)$ subject to (11) yields

$$
l(t)=\frac{\eta \hat{y}(t)}{R(t)}, c_{s}(t)=\frac{\gamma \hat{y}(t)}{p(t)}, c_{i}(t)=\xi \hat{y}(t), c_{Z}(t)=\frac{\varsigma \hat{y}(t)}{p_{Z}}, c_{x}(t)=\frac{\chi \hat{y}(t)}{p_{x}}, s(t)=\lambda \hat{y}(t),
$$

where

$$
\begin{aligned}
& \eta \equiv \rho \eta_{0}, \gamma \equiv \rho \gamma_{0}, \xi \equiv \rho \xi_{0}, \varsigma \equiv \rho \varsigma_{0}, \chi \equiv \rho \chi_{0}, \lambda \equiv \rho \lambda_{0}, \\
& \rho \equiv \frac{1}{\eta_{0}+\gamma_{0}+\xi_{0}+\varsigma_{0}+\chi_{0}+\lambda_{0}} .
\end{aligned}
$$


The definition of $s(t)$ results in the following equation for wealth change

$$
\dot{\bar{k}}(t)=s(t)-\bar{k}(t) \text {. }
$$

Equation (13) tells that the saving minus the dissaving equals the change in wealth.

\subsection{Full Use of Land and Demand of and Supply for Services}

The national land is distributed between the residential use and service production

$$
l(t) N+L_{s}(t)=L
$$

The equilibrium condition for services implies

$$
c_{s}(t) N=F_{s}(t) .
$$

The GDP is defined as

$$
Y(t)=F_{i}(t)+p(t) F_{s}(t)+l(t) N
$$

\subsection{Trade Balance}

We use $\bar{K}(t)$ to stand for the total wealth owned by the country. We get $\bar{K}(t)=\bar{k}(t) N$. The capital stocks employed by the country does not necessarily equal the national capital owned by the population. We define balance of trade $E(t)$ as follows

$$
E(t)=r^{*}(\bar{K}(t)-K(t))
$$

We thus constructed the dynamic growth model of a small open economy with endogenous wealth. The economy produces an exportable good and services. The economy uses land, labor and capital to produce goods and services. It imports energy. It includes many variables and relations among economic agents. The rest of paper examines behavior of the dynamic system.

\section{The Dynamics of the National Economy}

The appendix proves that a single differential equation describes the motion of the economic system. The following lemma demonstrates how the motion of all the variables in the dynamic system can be determined.

\subsection{Lemma}

We uniquely determine the variables, $k_{i}, x_{i}, k_{s}, x_{s}$, and $w$ as functions of $r^{*}$ and $p_{x}$ by (3) and (6). The motion of the land rent follows the following differential equation 


$$
\dot{R}(t)=\bar{\Lambda}(R(t)),
$$

in which we determine $\bar{\Lambda}$ as a function of $R(t)$ in the appendix. All the other variables are determined as functions of $R$ as follows:

$$
R(t): \bar{k}(t) \text { by (A10) } \rightarrow K(t) \text { by (A9) } \rightarrow p(t) \text { by (A8) } \rightarrow K_{i}(t) \text { and } K_{s}(t) \text { by (A1) } \rightarrow N_{i}(t)
$$

and $N_{s}(t)$ by (A1) $\rightarrow X_{i}(t)=x_{i}(t) N_{i}(t) \rightarrow X_{s}(t)=x_{s}(t) N_{s}(t) \rightarrow \hat{y}(t)$ by (A4) $\rightarrow l(t), c_{i}(t)$, $c_{s}(t), c_{Z}(t), c_{x}(t), s(t)$ by $(12) \rightarrow L_{s}(t)$ by $(14) \rightarrow F_{i}(t)$ by $(1) \rightarrow F_{s}(t)$ by (4).

The lemma means that the motion of economic system at any point in time is unique functions of the land rent and the other exogenous variables (the rate of interest, the prices of energy and foreign good, land resource, technology, and preference). If we know the motion of land rent, we can plot the motion of the whole system. It should be noted that many studies deal with effects of changes in a country's terms of trade on the economy's growth (e.g., Mendosa, 1995; Kose, 2002; and Turnovsky and Chattopadhyay, 2003). Eicher et al. (2008) state, "Previous authors have specified the borrowing cost to increase with the nation's level of debt. This specification, together with a constant rate of time preference and inelastic labor supply, implies that terms of trade shocks have no dynamic effects. The only response is that consumption fully adjusts instantaneously, with the current account remained unchanged." As shown below, our study has similar conclusions. To see this, we show in the appendix that the disposable income $\hat{y}(t)$ is independent of the price of imported good $p_{Z}$. The price has impact on the system only through the equation, $p_{Z} c_{Z}(t)=\varsigma \hat{y}(t)$. Accordingly we get

$$
\frac{d c_{Z}(t)}{d p_{Z}}=-\frac{c_{Z}(t)}{p_{Z}} .
$$

We see that the change in the price (terms of trade) does not have impact on the other variables in the dynamic system, except on the purchase of imported goods. As observed by Harberger (1950) and Laursen and Metzler (1950), a deterioration in the terms of trade reduces real income. The reduction in real income will lower saving and investment. Hence, the current account balance is deteriorated. Our study does not predict the Harberger-Laursen-Metzler effect. As observed by Eicher et al. (2008), the effect is sensitive to some determinants of the economy. These 
variables are, for instance, preferences (e.g., Mansoorian, 1993; Ikeda, 2001) and international capital market imperfections (Obstfeld, 1982).

For illustration we simulate the model. We specify parameter values as follows

$$
\begin{aligned}
& r^{*}=0.06, \quad p_{Z}=4, p_{Z}=6, \delta_{k}=0.05, \quad N=10, L=1, A_{i}=1.5, A_{s}=1, \alpha_{i}=0.3, \\
& \beta_{i}=0.6, \alpha_{s}=0.2, \quad \beta_{s}=0.5, b_{s}=0.1, \lambda_{0}=0.6, \xi_{0}=0.15, \gamma_{0}=0.06, \eta_{0}=0.1, \\
& \varsigma_{0}=0.04, \chi_{0}=0.06 .
\end{aligned}
$$

The rate of interest is fixed at 6 per cent. We chose the population 10 . The land is fixed at unity. We specify the propensity to save at 0.6 and the propensity to consume the industrial good at 0.15. The propensity to consume the industrial good is higher than the propensity to consume services, or propensity to consume imported goods, or to consume housing. The specified parameter values are not according to empirical observations. But it does not seem that the choice is unrealistic. For instance, some empirical studies on the US economy demonstrate that the value of the parameter, $\alpha$, in the Cobb-Douglas production is approximately equal to 0.3 . The choices of population and land will not affect our comparative dynamic analysis. Following the lemma, we determine the variables. We calculate the time-independent variables as follows

$$
k_{i}=4.47, k_{s}=3.58, w=0.98, x_{i}=0.027, x_{s}=0.009 .
$$

We choose the initial condition $R(0)=6$. The motion of the dynamic system is plotted in Figure 1. As the initial value of the land is fixed higher than its long-term equilibrium value, we see that the land rent falls over time. The price of services is reduced over time. The lot size and the land used by the service sector are not changeable. The consumption levels of the good, energy, foreign good, and services fall. The output of the industrial sector rises. The output of the service sector falls. The labor force is shifted from the service sector to the industrial sector. The capital stocks employed by the economy and the industrial sector are increased. The capital stock employed by the service sector is reduced. The amount of energy used by the industrial sector rises, while that by the service sector falls. 

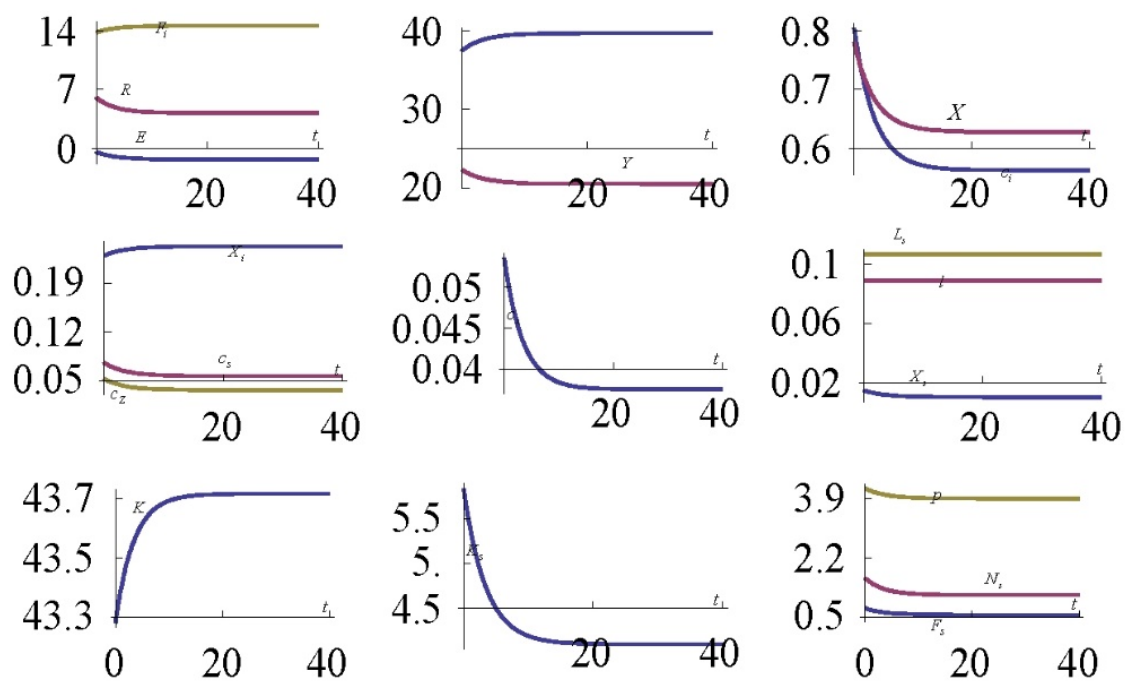

Figure 1. The Motion of the National Economy.

Figure 1 shows how the system approaches its equilibrium point. We calculate the equilibrium values of the variables as follows

$$
\begin{gathered}
p=3.92, R=4.21, Y=20.54, X=0.63, E=-1.27, K=43.72, \bar{K}=22.54, N_{i}=8.85, \\
N_{s}=1.15, K_{i}=39.62, K_{s}=4.10, X_{i}=0.24, X_{s}=0.10, L_{s}=0.11, F_{i}=14.53, F_{s}=0.58, \\
c_{i}=0.56, c_{s}=0.06, c_{Z}=0.04, c_{x}=0.04, l=0.09 .
\end{gathered}
$$

The eigenvalue at the equilibrium point equals -0.29 . The unique equilibrium point is stable. The stability of the equilibrium point is also identified with varying initial conditions.

\section{Comparative Dynamic Analysis}

The previous section plotted the motion of the small-open economy. We now deal with how changes in some parameters affect the national economy. As we are able to follow the motion of the system, it is straightforward for us to examine the impact of changes in any parameter. Before conducting comparative dynamic analysis, we introduce a variable, $\bar{\Delta} x(t)$, to stand for the change rate of the variable, $x(t)$, in percentage due to changes in the parameter value.

\subsection{A Rise in the Price of Imported Energy}

First, we study the impact of the following change in the price of imported energy: $p_{x}: 6 \Rightarrow 6.5$. The capital intensities, the wage rate and energy intensities are affected as follows 


$$
\Delta k_{i}=\Delta k_{s}=\Delta w=-1.33, \Delta x_{i}=-8.92, \Delta x_{s}=-7.69 \text {. }
$$

The rise in the imported energy price reduces the capital intensities, the wage rate and energy intensities. The effects on changes in the time-dependent variables are plotted in Figure 2. The amount of energy used by the two sectors and the households and the total amount of energy imported are reduced. Initially some of the labor force is shifted from the industrial sector to the service sector. Nevertheless, in the long term the labor distribution is not affected by the change in the energy price. The land distribution is almost not affected. The land rent falls over time. The capital stocks the two sectors and the total capital employed by the economy are all reduced. The trade balance is improved in association with the falls in the GDP. The consumption levels of the good, the service, the energy, and the imported good are all reduced. The GDP and national wealth are reduced. As observed by Hamilton (1983, 2003), economic recessions are closely related to energy price shocks. Our study predicts that a rise in the energy price has negative effects on the economy.
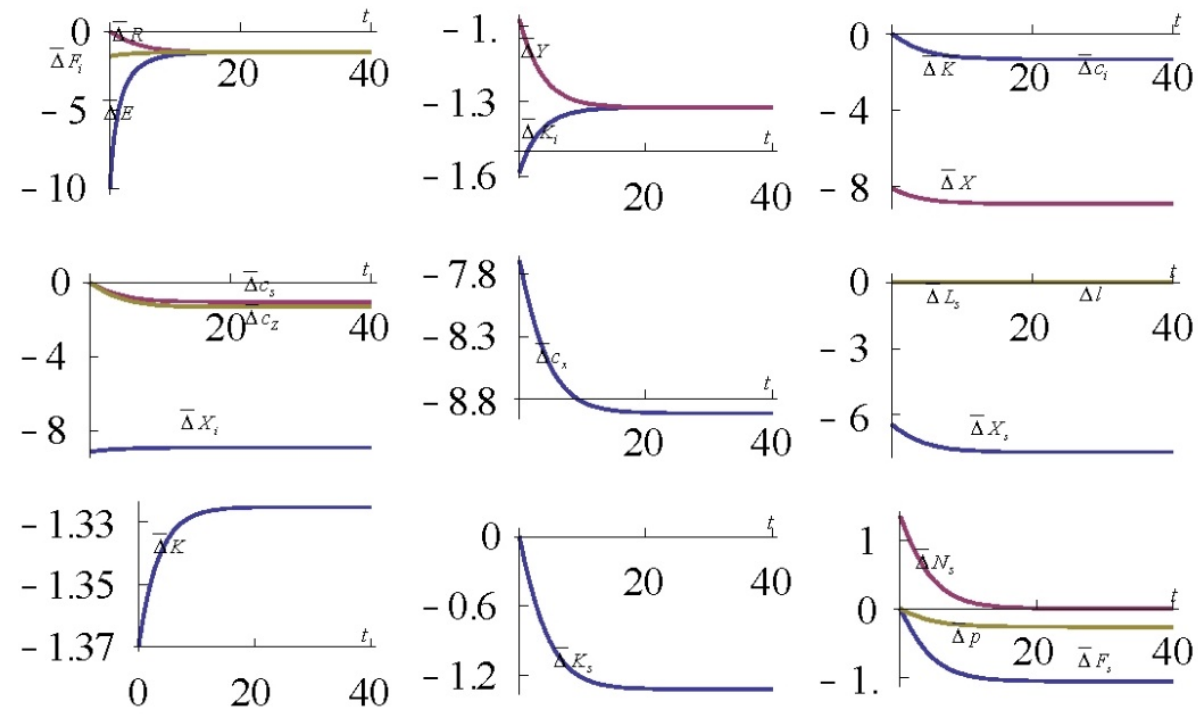

Figure 2. A Rise in the Price of the Imported Energy

\subsection{A Rise in the Propensity to Consume Imported Goods}

We now allow the propensity to consume imported goods to be changed as follows: $\varsigma_{0}: 0.04 \Rightarrow 0.05$. The capital intensities, the wage rate, and the energy intensities are not affected. This is due to that these variables are only related to the rate of interest and technologies. The changes in the time-dependent variables are plotted in Figure 3. The rise in the propensity increases 
the consumption level of the imported good. The economy consumes less on the consumption of the imported energy and services. The consumption on the industrial good rises initially but falls in the long term. The trade balance is improved initially but is deteriorated in the long term. The output level of the industrial sector is enhanced. The output level of the service sector falls. The labor force redistribution is associated with reduction in the service price. The energy input of the industrial sector is almost not affected. The industrial sector's input level of capital is increased, while that the service sector's is reduced. As the consumer consumes more the foreign good, the GDP is reduced.
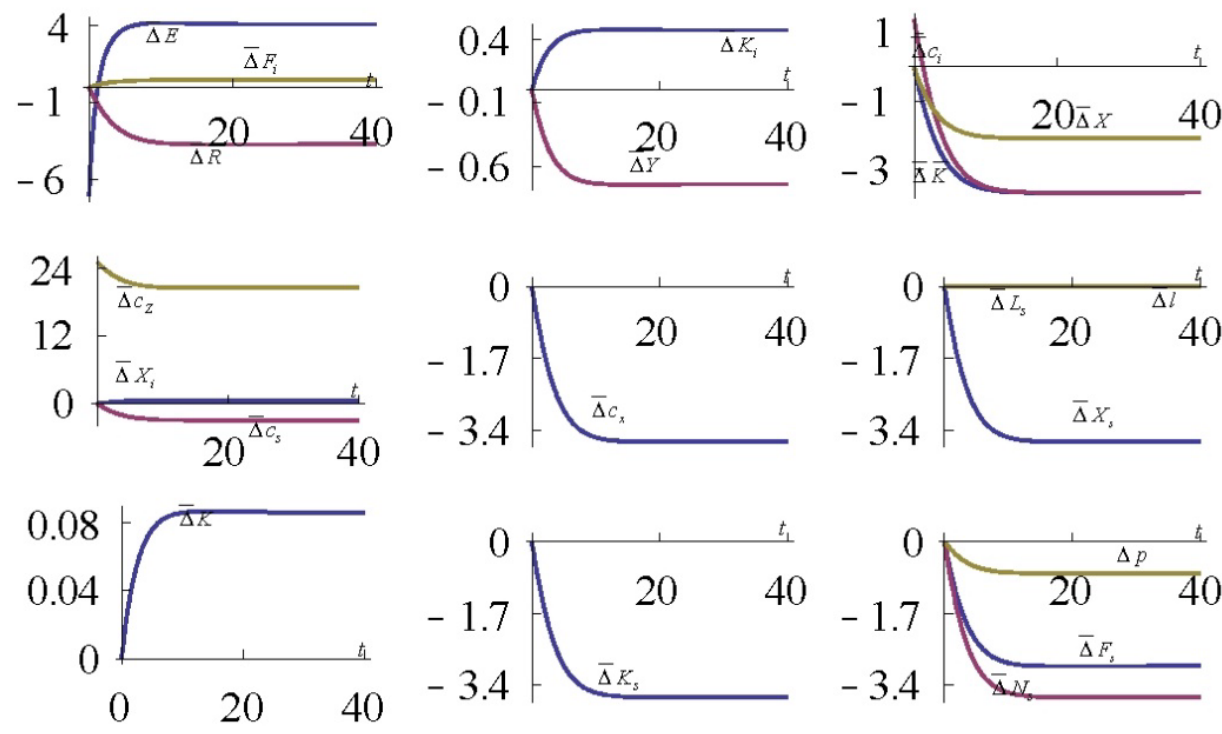

Figure 3. An Increase in the Propensity to Consume Imported Goods

\subsection{A Rise in the Rate of Interest}

We now study the case of $r^{*}=0.06 \Rightarrow 0.065$. The rise in capital cost reduces the capital intensities, the wage rate and the energy intensities as follows

$$
\Delta k_{i}=\Delta k_{s}=-6.45, \Delta w=\Delta x_{i}=-2.20, \Delta x_{s}=4.55 .
$$

The time-dependent variables are plotted as in Figure 4. The rising cost of capital makes the two sectors to employ less capital. The national economy employs less capital. The net consequence of reduced wage income and increased rate of interest leads to a fall in the wealth. The price of service is increased. The output levels of the two sectors fall in response to the increased production cost. Some of the labor force is shifted from the industrial sector to the service sector. The GDP falls 
over time. The trade balance is improved as the fall in the foreign capital used by the economy is the greater than the fall in the national wealth. The land rent is slightly reduced.
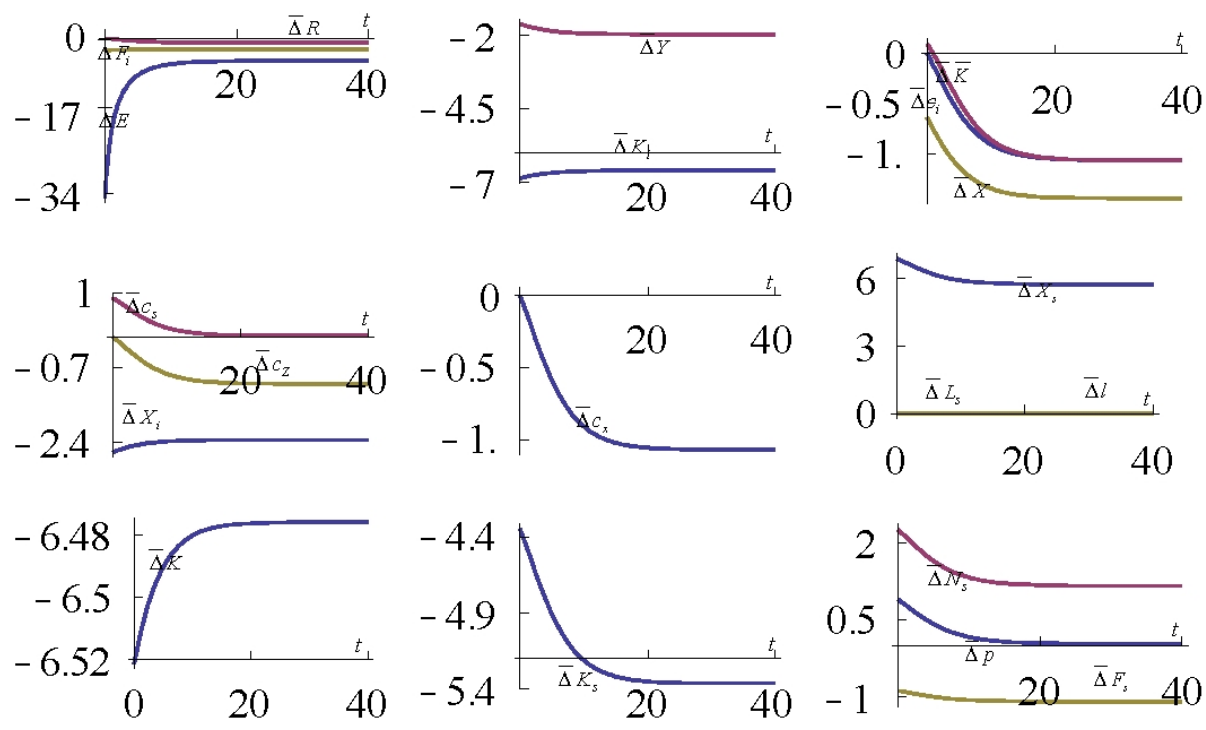

Figure 4. An Increase in the Rate of Interest

\subsection{A Rise in the Propensity to Save}

We now allow the propensity to save to be changed as follows: $\lambda_{0}=0.6 \Rightarrow 0.65$. The capital intensities, wage rate and energy intensities are not affected. The changes in the timedependent variables are plotted in Figure 5. The rise in the propensity to save enhances the national wealth and the GDP. The land rent and price of service are enhanced. Some of the labor force is shifted from the industrial sector to the service sector. The output level of the industrial sector is almost not changed. The output level of the service sector is raised. The industrial sector uses less energy. The household and service sector use more energy. The economy imports more energy. The consumption levels of service, imported good, energy and industrial good are all increased. It should be noted that this conclusion is not the same as what one finds in the Solow growth model for a closed economy where an enhanced propensity to save reduces consumption level. In the small open economy, a rise in the propensity to save makes the economy to use less foreign capital. As the household has more disposable incomes, the household spends more on consuming. When people save more from their disposable income, both their wealth and consumption are increased. 

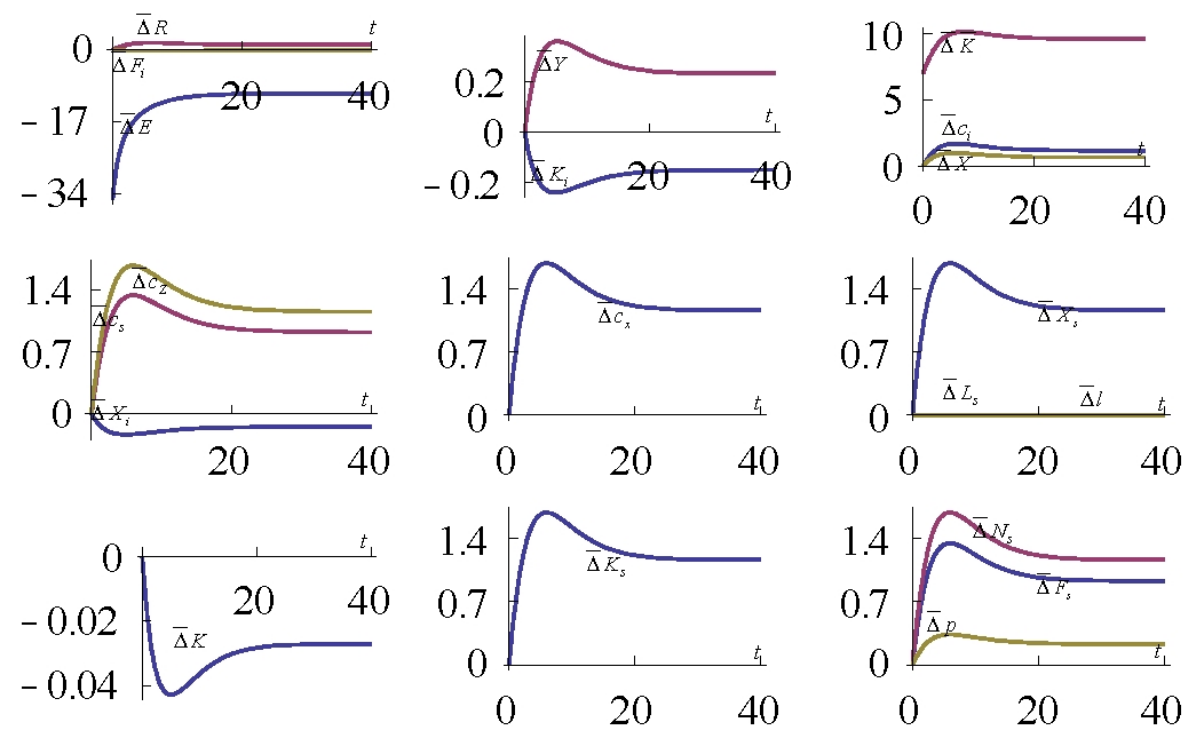

Figure 5. A Rise in the Propensity to Save

\section{Conclusions}

This paper built an economic growth model of a small open economy with imported energy and goods in a perfectly competitive economy. Following the traditional literature of small open economies, we assume that the rate of interest and prices of imported energy and goods are fixed in the international market. The production side is the same as in the neoclassical growth theory. We simulated the model and demonstrated that the system has a unique stable equilibrium point. We examined the effects of changes in the price of energy, the propensity to consume foreign good, the rate of interest, and the propensity to save. The comparative dynamic analysis provides some insights. For instance, an oil crisis has negative effects on almost all the variables in the economic system. We also demonstrated that as the propensity to consume foreign brands is increased, the GDP is reduced and the demand for imported goods is increased. The economy spends less on the consumption of the imported energy and goods. The consumption of the industrial good rises initially but falls in the long term. The trade balance is improved initially but is deteriorated in the long term. The output level of the industrial sector is increased, while output level of the service sector is reduced. The energy input of the industrial sector is slightly affected, while that of the service sector is reduced. The industrial sector's input level of capital is increased, while that the service sector's is reduced. The paper provides some implications for government policy. For instance, it would encourage national long-term development by enhancing the propensity to save. 
As a rise in the propensity to consume imported goods will harm national economic interest, it would benefit the country to encourage consuming domestic goods rather than imported goods. Although it includes many important determinants of economic growth, the model may be generalized to include other possibly important determinants of growth, for instance, endogenous human capital and government intervention in trade.

\section{References}

Backus, D. K., \& Crucini, M. J. (2000). Oil prices and the terms of trade. Journal of International Economics, 50(1), 185-213.

Brock, P.L. (1988). Investment, the current account, and the relative price of non-traded goods in a small open economy. Journal of International Economics, 24(3-4), 235-53.

Hamilton, J. D. (1983). Oil and the macroeconomy since World War II. Journal of Political Economy, 91(2), 228-48.

Hamilton, J.D. (2003) What Is an Oil Shock? Journal of Econometrics 113(2), 363-98.

Eicher, T. S., Schubert, S. F., \& Turnovsky, S. J. (2008). Dynamic effects of terms of trade shocks: The impact on debt and growth. Journal of International Money and Finance, 27(6), 876-96.

Harberger, A. C. (1950). Currency depreciation, income, and the balance of trade. Journal of Political Economy, 58(1), 47-60.

Ikeda, S. (2001). Weakly non-separable preferences and the Harberger-Laursen-Metzler Effect. Canadian Journal of Economics, 34(1), 290-307.

Kanemoto, Y. (1980). Theories of urban externalities. Amsterdam: North-Holland.

Kim, I., \& Loungani, P. (1992). The role of energy in real business cycle models. Journal of Monetary Economics, 29(2), 173-89.

Kose, M. A. (2002). Explaining business cycles in small open economies: How much do World prices matter?. Journal of International Economics, 56(2), 299-327.

Laursen, S., \& Metzler, L. A. (1950). Flexible exchange rates and the theory of employment. Review of Economics and Statistics, 32(4), 281-99.

Mansoorian, A. (1993). Habit persistence and the Harberger-Laursen-Metzler Effect in an infinite horizon model. Journal of International Economics, 34(1-2), 153-66.

Marin-Pantelescu, A. \& Tigu, G. (2010). Features of the travel and tourism industry which may affect pricing. Journal of Environmental Management and Tourism, 1(1), 8-11.

Matsuyama, K. (1987). Current account dynamics in a finite horizon model. Journal of International Economics, 23(3-4), 299-313.

Mendosa, E. G. (1995). The terms of trade, the real exchange rate, and economic fluctuations. International Economic Review, 36(1), 101-37. 
Obstfeld, M. (1982). Aggregate spending and the terms of trade: Is there a Harberger-LaursenMetzler Effect?. Quarterly Journal of Economics, 97(2), 251-70.

Sachs, J. (1982). The current account in the macroeconomic adjustment process. Scandinavian Journal of Economics, 84(2), 147-59.

Schubert, S. F., \& Brida, J. G. (2009). A dynamic model of economic growth in a small tourism driven economy. Munich Personal RePEc Archive.

Schubert, S. F., \& Turnovsky, S. J. (2011). The impact of oil prices on an oil-importing developing economy. Journal of Development Economics, 94(1), 18-29.

Svensson, L. E. O., \& Razin, A. (1983). The terms of trade and the current account: The HarbergerLaursen-Metzler Effect. Journal of Political Economy, 91(1), 97-125.

Turnovsky, S. J. \& Chattopadhyay, P. (2003). Volatility and growth in developing economies: Some numerical results and empirical evidence. Journal of International Economics, 59(2), 26795.

Uzawa, H. (1961). On a two-sector model of economic growth. Review of Economic Studies, 29(1), 47-70.

Zhang, W. B. (2005). Economic growth theory. London: Ashgate.

Zhang, W. B. (2008). International trade theory: Capital, knowledge, economic structure, money and prices over time and space. Berlin: Springer.

Zhang, W. B. (2013). The impact of transport, land and fiscal policy on housing and economic geography in a small-open growth model. Journal of Transport and Land Use, 6(1), 89100 . 


\section{Appendix: Proving Lemma 1}

We already showed that we $k_{i}, w$, and $k_{s}$ are determined as functions of $r^{*}$ and $p_{x}$. The variables $r^{*}$ and $p_{x}$ are given in the international market. From $K_{j}=k_{j} N_{j}$ and (8), we get

$$
K_{i}=\left(K-k_{s} N\right) k_{0} k_{i}, K_{s}=\left(k_{i} N-K\right) k_{0} k_{s} .
$$

In (A1) and the rest of the appendix we omit time variable in expressions. From (5), $l_{s}=L_{s} / N_{s}$ and $w_{s} \equiv w \gamma_{s} / \beta_{s}$, we get

$$
R=\frac{w_{s} N_{s}}{L_{s}}
$$

Inserting (A2) in (15) yields

$$
l N+\frac{w_{s} N_{s}}{R}=L
$$

The definition of $\hat{y}$ implies

$$
\hat{y}=\left(1+r^{*}\right) \bar{k}+w+\frac{R L}{N} .
$$

From (A4) and $l=\eta \hat{y} / R$ in (13), we get

$$
l=\frac{\left(1+r^{*}\right) \eta \bar{k}+\eta w}{R}+\frac{\eta L}{N} .
$$

Inserting this equation in (A3) yields

$$
\left(1+r^{*}\right) \eta \bar{k}+\eta w+\frac{w_{s} N_{s}}{N}=(1-\eta) \frac{L}{N} R
$$

From $r_{\delta}=\alpha_{s} p F_{s} / K_{s}$ and (15) we get

$$
c_{s} N=\frac{r_{\delta} K_{s}}{\alpha_{s} p} .
$$

Substitute $c_{s}=\gamma \hat{y} / p$ into (A6)

$$
\gamma \hat{y} N=\frac{r_{\delta} K_{s}}{\alpha_{s}} .
$$

Inserting (A4) in this equation yields

$$
\left(\left(1+r^{*}\right) \bar{k}+w+\frac{R L}{N}\right) \gamma N=\frac{r_{\delta} K_{s}}{\alpha_{s}} .
$$


Equation (5) and $l_{s}=w_{s} / R$ implies

$$
p=\frac{R^{\gamma_{s}}}{\gamma_{s} A_{s} w_{s}^{\gamma_{s}-1} k_{s}^{\alpha_{s}} x_{s}^{b_{s}}} .
$$

Inserting $N_{s}=\left(k_{i} N-K\right) k_{0}$ from (8) in (A5) and $K_{s}=\left(k_{i} N-K\right) k_{0} k_{s}$ from (A1) in (A7), respectively, we have

$$
\begin{aligned}
& \left(1+r^{*}\right) \eta N \bar{k}-w_{s} k_{0} K=\bar{\Psi} \\
& \left(1+r^{*}\right) \gamma N \bar{k}+\frac{r_{\delta} k_{0} k_{s} K}{\alpha_{s}}=\widetilde{\Psi},
\end{aligned}
$$

where

$$
\begin{aligned}
& \bar{\Psi}(R(t))=(1-\eta) L R-\eta w N-w_{s} k_{i} k_{0} N, \\
& \widetilde{\Psi}(R(t)) \equiv \frac{k_{i} N r_{\delta} k_{0} k_{s}}{\alpha_{s}}-w \gamma N-R L \gamma .
\end{aligned}
$$

Solve (A9)

$$
\bar{k}=\Psi(R) \equiv \frac{1}{\left(1+r^{*}\right) N}\left(\widetilde{\Psi}+\frac{r_{\delta} k_{s} \bar{\Psi}}{\alpha_{s} w_{s}}\right)\left(\gamma+\frac{\eta r_{\delta} k_{s}}{\alpha_{s} w_{s}}\right)^{-1} .
$$

Following the following procedure all the variables are expressed as functions of $R: \bar{k}$ by $(\mathrm{A} 10) \rightarrow K$ by $(\mathrm{A} 9) \rightarrow p$ by (A8) $\rightarrow K_{i}$ and $K_{s}$ by (A1) $\rightarrow N_{i}$ and $N_{s}$ by (A1) $\rightarrow \hat{y}$ by (A4) $\rightarrow l, c_{i}, c_{s}, c_{Z}, c_{x}, s$ by (12) $\rightarrow L_{s}$ by (14) $\rightarrow F_{i}$ by (1) $\rightarrow F_{s}$ by (4). This procedure and (13) imply

$$
\dot{\bar{k}}=\Lambda(R) \equiv \lambda \hat{y}-\bar{k}
$$

Take derivatives of (A10) with respect to time

$$
\dot{\bar{k}}=\frac{d \Psi}{d R} \dot{R}
$$

The expression of $d \Psi / d R$ are not provided as it is tedious. Equations (A11) and (A12) imply

$$
\dot{R}=\bar{\Lambda}(R) \equiv \Lambda\left(\frac{d \Psi}{d R}\right)^{-1}
$$

We proved the lemma. 